\title{
EL DERECHO Y LA CONTINGENCIA DE LO POLÍTICO
}

\author{
F. Atria* \\ Universidad de Chile
}

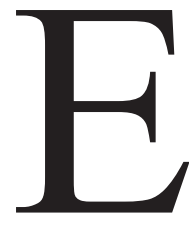

n este artículo quiero discutir sobre el control de constitucionalidad. Por 'control de constitucionalidad' entenderé principalmente el control jurisdiccional de constitucionalidad, a pesar de que es importante tener en mente que el control constitucional puede ser ejercicio (y normalmente lo es) de muchas maneras, incluso por los ciudadanos. Con la constitución de 1980 se ha establecido entre nosotros, sin embargo, la idea de que la constitución es una ley (fundamental, sí, pero ley al fin) análoga (salvo en su jerarquía) a las demás leyes, y por eso se ha llegado a la conclusión, prácticamente unánime, de que el control de la constitución exige un tribunal, del mismo modo que el cumplimiento de las reglas del Código Civil descansa, en última instancia, en un tribunal con potestad para ordenar su cumplimiento. Es esta idea la que quiero objetar. Ustedes podrán haber escuchado que esta idea a veces se fundamenta por analogía con historia de Ulises y las Sirenas ${ }^{1}$. En La Odisea Ulises (como el pueblo en momentos constitucionales) le ordena a su tripulación que lo ate al palo mayor para que pueda oír el canto de las Sirenas, pero que no lo liberen aunque él se lo pida o se lo ordene. De esta manera Ulises pudo, por un lado, oír el canto de las sirenas y, por otro, evitar la suerte de todos los que, fascinados (como el pueblo, se dice, en momentos de paroxismo) por el canto de las sirenas, naufragaban en sus arrecifes. Si menciono esta historia no es porque crea que provee de justificación al con-

* Universidad Adolfo Ibáñez, Universidad de Chile (fernando.atria@uai.cl). Este artículo es una versión, ojalá mejorada, de la ponencia presentada al Primer Congreso Estudiantil de Derecho y Teoría Constitucional, organizado por el Centro de Alumnos de la Facultad de Derecho de la Universida de Chile y realizado en Santiago entre los días 6 y 9 de Agosto de 2003. Mis agradecimientos a la comisión organizadora por la invitación. La investigación de la que este artículo forma parte es financiada por FONDECYT (proyecto 1010461).

${ }^{1}$ Elster, Ulises y las Sirenas. 
trol jurisdiccional de constitucionalidad (no lo hace ${ }^{2}$ ), sino porque espero mostrar que la promesa del control jurisdiccional de constitucionalidad, i.e. la ilusión de que podemos escapar de la contingencia de la política, es el canto de las sirenas, que hoy nos encanta y nos ha hecho sacrificar (o aceptar la imposición de la pérdida, para ser más fieles a la historia de la constitución de 1980) algunas de las características más notables de la tradición jurídica y política chilena bajo la vigencia de la constitución de $1925^{3}$.

\section{El tema de este artículo (I): Tres respuestas incorrectas}

Para llegar a esta conclusión debemos previamente ralear el campo. Por eso, y exponiéndome al riesgo de decir algunas trivialidades, permítanme mencionar algunos temas que no estamos discutiendo al discutir la cuestión de la protección jurisdiccional de la constitución ${ }^{4}$.

\section{La supremacía de la constitución}

Desde que la Corte Suprema norteamericana decidiera el famoso caso Marbury v. Madison en 1804, es común creer que al discutir el problema del control de constitucionalidad de las leyes estamos preguntándonos sobre si hemos de considerar a la Constitución la norma suprema del sistema jurídico. Como se sabe, la corte de Marbury decidió, sin texto constitucional que la autorizara explícitamente para ello, arrogarse jurisdicción para conocer de reclamos de constitucionalidad de una ley. El fundamento de su decisión fue la idea de que, si la constitución era la ley suprema, entonces los jueces llamados a aplicar el derecho debían pronunciarse sobre la inconstitucionalidad de una ley ordinaria, porque debían poder decir cuál era el derecho que correspondía aplicar ${ }^{5}$. Siguiendo una argumentación similar a la lógica de Marshall, muchos hoy repiten que sólo puede afirmarse que un sistema jurídico se sujeta al ideal de la supremacía de la constitución si las leyes contrarias a la constitución pueden ser invalidadas por un órgano judicial, más o menos 'ordinario'.

Pero este argumento es evidentemente falaz ${ }^{6}$. ¿Qué pasa, por ejemplo, con un juez de primera instancia que, después de haber visto su sentencia

\footnotetext{
${ }^{2}$ Véase Waldron, Law and Disagreement.

${ }^{3}$ No me referiré a esa tradición en este artículo. Algo ya he dicho en Atria, "Inaplicabilidad y coherencia".

${ }^{4}$ De hecho, yo creo que lo que sigue es bastante trivial, pero es necesario volver a las trivialidades cuando ellas son negadas.

${ }^{5}$ Para una exposición y crítica del argumento del Juez Marshall en Marbury v. Madison, véase Nino, "Fundamentos del control judicial" 98-102.
} 
revocada por el juez superior, llega a la conclusión de que la sentencia de segunda instancia es inconstitucional y se niega en virtud de ello a dictar el 'cúmplase'? ¿O con el carabinero que debe hacer cumplir una ley que a su juicio es inconstitucional? Me parece claro que en ningún sentido sensato la idea de supremacía constitucional puede significar que cualquier funcionario puede declarar la inconstitucionalidad de una regla, a menos que queramos decir que el carabinero y el juez de primera instancia tienen el deber constitucional de declarar la nulidad de la ley o de la sentencia de segunda instancia.

La razón que explica lo anterior es que el derecho es un sistema formal, es decir, un sistema elaborado sobre la base de una más o menos sofisticada red de competencias e incompetencias. Como consecuencia de esto, no basta que una acción o decisión sea contraria a derecho para que haya alguien autorizado a declararlo: no basta que un contrato sea ilegal para que un juez tenga competencia para declararlo (se requiere que una parte solicite la nulidad, o que la nulidad, si es absoluta, aparezca de manifiesto en el acto o contrato, conforme al art. 1682 CC); no basta que una sentencia sea contraria a la ley para que cualquier juez tenga competencia para declararlo así, no basta que una ley sea contraria a la constitución para que cualquier juez tenga competencia para declarar su invalidez ${ }^{7}$.

A pesar de lo anterior, no tenemos problema en decir que la ley prima sobre el contrato, la sentencia de segunda instancia sobre la de primera, la constitución sobre la ley.

Aun si el argumento anterior no se aceptara sería todavía posible seguir rechazando la conclusión de Marshall: reconocer la constitución como suprema nada dice sobre qué órgano es el llamado a aplicarla. La constitución puede ser aplicada por un tribunal ordinario o todos los tribunales ordinarios, puede ser aplicada por un tribunal constitucional...o por el parlamento mismo. En resumen, cuando la pregunta es "¿ha de tener un órgano judicial la última palabra respecto de la interpretación de la constitución?”, la idea de supremacía constitucional no la responde.

\footnotetext{
${ }^{6}$ Adicionalmente a Nino (cit. supra. N 5), véase Troper, "Logic of justification of judicial review" 103-109.

${ }^{7}$ Esto es básicamente una reiteración del (correcto) argumento kelseniano de que el derecho no conoce normas nulas, sino anulables. Y el corolario obvio de que del hecho de que haya una norma anulable no se sigue que cualquier órgano tiene competencia para declarar esa nulidad. Véase Kelsen, Teoría Pura (1960).
} 
La existencia de derechos como límites a las decisiones mayoritarias

Si no es en la supremacía constitucional, algunos creen que pueden fundar la tesis de la revisabilidad judicial de la constitución en la existencia de derechos entendidos (a la manera del art. $5^{\circ}$ de la constitución chilena) como "limites a la soberanía". Como el legislador ejerce soberanía, y la soberanía reconoce en esos derechos límites, cuando el legislador traspasa esos límites actúa viciadamente, y cuando actúa viciadamente se requiere un juez que así lo declare.

De nuevo, la conclusión es apresurada. Si el argumento fuera plausible, estaríamos obligados a concluir que los derechos no obligan a la Corte $\mathrm{Su}-$ prema cuando falla en casación, por la sencilla razón de que no hay recurso alguno en contra de su decisión, o al tribunal constitucional, cuando decide sobre la constitucionalidad de un proyecto. Siempre hay alguna autoridad que tiene la última palabra respecto de un problema substantivo (cuando el problema es suficientemente serio), y esa última palabra no vale definitivamente porque esté en lo correcto, vale porque es la última ${ }^{8}$.

Como ustedes pueden ver, el argumento para responder estos dos primeros intentos de fundar el control de constitucionalidad es el mismo: en ambos casos el argumento inicial es que hay una estándar normativo $\mathrm{X}$ (la constitución, los derechos fundamentales) que es (o debe ser) supremo respecto de otros estándares normativos, y se nos invita a aceptar que reconocerle supremacía a estos estándares normativos (la constitución o los derechos) significa crear mecanismos institucionales que permitan declarar inválido cualquier estándar que los contravengan.

En ambos casos la respuesta es la misma, y la verdad es que es una respuesta que está muy cerca de constituir la clave para entender el derecho, al menos el derecho moderno. El derecho tiene autoridad, y que el derecho tenga autoridad quiere decir que las reglas jurídicas valen no porque sean correctas, sino porque son jurídicas ${ }^{9}$. Es perfectamente inútil que el juez diga, al fallar sobre la demanda del comprador contra el vendedor, "el vendedor debe hacer lo que es justo que haga”. Y esta respuesta es inútil porque fue el desacuerdo sobre qué es justo que el vendedor haga lo que llevó a las partes a juicio; lo que el juez debe hacer al fallar es dar una respuesta cuyo contenido las partes puedan conocer a pesar de estar en desacuerdo sobre qué es justo que hagan. Lo mismo vale para el legislador. Sería per-

\footnotetext{
${ }^{8}$ Como sostuvo Schmitt, una sentencia judicial vale no porque contiene "una argumentación que pretenda convencer a todos, sino [...] una decisión que se limita a suprimir la duda de un modo autoritario" (Schmitt, Defensa de la Constitución 61).

${ }^{9}$ La mejor formulación de este argumento, aunque lo lleva a consecuencias incorrectas, está en Raz, "Authority, Law and Morality".
} 
fectamente inútil que el legislador dijera "debe pagarse como IVA lo que es justo pagar como IVA"; el legislador debe dictar, a los ciudadanos, una regla que pueda ser identificada por personas que tienen diversas ideas sobre la justicia de la obligación tributaria, desde el anarco-capitalista que cree que pagar impuestos es esclavitud hasta el colectivista que cree que el sistema tributario debe estar orientado a producir igualdad completa entre todos los ciudadanos al final de cada ejercicio tributario.

\section{Evitar el terror}

Una tercera respuesta a nuestra pregunta, “¿qué es lo que estamos discutiendo al discutir sobre control judicial de constitucionalidad?" es la siguiente: el siglo XX nos ha enseñado que las decisiones mayoritarias pueden violar derechos. No porque sea una decisión mayoritaria la limpieza étnica es aceptable. Por consiguiente, deben existir mecanismos institucionales que permitan cuestionar la validez substantiva de una decisión mayoritaria, de modo de poder evitar el terror incluso cuando, como en Alemania en los años 30, éste sea democráticamente elegido. Entre esos mecanismos está el control judicial de constitucionalidad.

Pero esta respuesta es incorrecta, porque las instituciones judiciales no sirven para evitar el terror. Y no sirven porque las instituciones judiciales no son el tipo de instituciones que puedan resistir el terror. Cuando aparece el terror, los tribunales o hacen su contribución a él (como los tribunales chilenos con los miles de recursos de amparo rechazados durante el terror y los vergonzosos discursos inaugurales de esos años ${ }^{10}$ ), o son intervenidos. Para una dictadura como la chilena, que detenta el poder necesario para desencadenar el terror y para aprobar la constitución por decreto-ley, no es muy difícil modificar la composición de un tribunal por decreto-ley ${ }^{11}$.

Los dos primero argumentos yerran el blanco porque no entienden la estructura del derecho: el derecho no vale porque sea correcto sino vale porque es derecho. Y esto no es un defecto del derecho, es precisamente su virtud, porque es precisamente esto lo que nos permite tener derecho aun cuando estemos en desacuerdo sobre lo que es correcto. El tercer argumento yerra porque espera del derecho una cosa que el derecho no puede dar: el derecho no puede dar protección cuando el derecho está suspendido. Los primeros no entienden la fortaleza del derecho, el último no entiende su debilidad.

\footnotetext{
${ }^{10}$ Véase Comisión Nacional de Verdad y Reconciliación, Informe 97-104. Véase también Atria, "La hora del derecho" 52-57.

${ }^{11}$ Sobre este punto, véase Atria, "La hora del derecho", Atria, "Legalismo, política y derechos".
} 


\section{El tema de este artículo (II) Política y derecho}

¿De qué, entonces, estamos hablando? Quiero hacer un cuarto intento y veremos que con él llegaremos un poco más lejos. Este cuarto intento recuerda la famosa formulación del Tribunal Constitucional Federal de Alemania, que se ve a sí mismo asegurando 'la sujeción del derecho a la política' ${ }^{12}$. Entonces podemos decir que lo que estamos discutiendo aquí es: ¿Debe la política ser sujetada al derecho? Pero antes de responder esta pregunta es importante ver cómo el derecho podría sujetar a la política, y para eso lo mejor es ver los casos en los que el derecho sujeta al poderoso.

\section{Derecho y conflicto}

Usaremos el modelo de un conflicto de derecho privado: después de haber celebrado el contrato, y cuando ha llegado el momento de cumplirlo, el vendedor se niega a hacerlo aduciendo que de parte del comprador ha habido mala fe. El comprador cree que de su parte no ha habido mala fe, y lo demanda. La situación aquí es que hay dos partes que en algún momento en el pasado utilizaron ciertas reglas para crear una relación entre ellos y luego se encuentran que uno de ellos no quiere cumplir lo que habían acordado. Aquí cada parte está intentando maximizar su utilidad, y al mismo tiempo cada parte está decidiendo qué es lo que debe hacer bajo el contrato.

Para solucionar este conflicto, el derecho permite a cualquiera de las partes llevarlo ante un tercero imparcial, que conoce las reglas conforme a las cuales las partes crearon la relación contractual en cuestión, y que adicionalmente carece de cualquier interés personal en la resolución del mismo. Esta solución, de que el conflicto sea solucionado por un juez, es adecuada por dos razones:

En primer lugar, porque las reglas que el juez aplicará no son, en principio, extrañas a las partes ${ }^{13}$. Típicamente, las partes conocerán esas reglas al menos en cuanto ellas definen una práctica que ellas adicionalmente habrán hecho suya para establecer su relación. Por eso puede decirse que el juez aplica a las partes su propias reglas.

En segundo lugar, porque, típicamente de nuevo, las partes no estarán en desacuerdo sobre qué es lo correcto hacer en abstracto, sino sobre qué es lo que cada una de ellas debe hacer en concreto. El desacuerdo existe porque "el amor propio puede inclinar [a los hombres] a actuar con parcialidad, a

\footnotetext{
${ }^{12}$ Formulación adoptada, entre otros, por Peña, Práctica Constitucional y Derechos Fundamentales 198.

${ }^{13}$ Véase Detmold, "Law as Practical Reason”.
} 
favor suyo y en el de sus amistades"14: las partes tienen su juicio afectado por su envolvimiento en el problema.

Dentro del marco de una explicación como la anterior, que el derecho 'sujete' al poderoso quiere decir que la interpretación auto-interesada que el poderoso da a las reglas abstractas aplicables no es más fuerte por ser la interpretación del poderoso. El derecho 'soluciona' el conflicto mirando sólo a lo que, de acuerdo con las reglas jurídicas aplicables, es relevante, y excluyendo todo lo demás. En 'todo lo demás' resulta excluido el hecho de que el demandante es, por ejemplo, una poderosa y millonaria sociedad, mientras el demandado es una pobre viuda patrocinada por la Corporación de Asistencia Judicial.

Permítanme detenerme un minuto más en esta caracterización jurídica del conflicto, esta vez mirando a la decisión que lo resuelve ${ }^{15}$. Esa decisión se basa, al menos en los casos normales, en reglas abstractas que, como vimos, no puede decirse que sean reglas extrañas a las partes ${ }^{16}$; son, de hecho, las mismas reglas que las partes invocaron en el momento de crear su relación jurídica ${ }^{17}$. No estoy sosteniendo la tesis de que esa decisión se sigue silogísticamente de esas reglas, pero sí que esa decisión (se espera que) refleje el contenido de esas reglas aplicadas al caso $^{18}$. Y éste es el punto que quiero enfatizar aquí: la decisión refleja el contenido de las reglas abstractas comunes a las partes, no refleja el desacuerdo ni el contenido del desacuerdo entre las partes. Estrictamente hablando, el conflicto entre comprador y vendedor no es relevante para determinar la corrección de la decisión, en el sentido de que la decisión debería en principio ser la misma con o sin conflicto, porque la aplicación de esas reglas abstractas a ese caso debería llevar a la misma conclusión aunque las partes no hayan estado en desacuerdo. El conflicto, en consecuencia, configura la ocasión para la decisión (no habría habido juicio sin conflicto), pero no tiene impacto en lo que los abogados llaman 'lo dispositivo del fallo'.

De lo anterior se sigue otro aspecto importante de esta forma de solucionar conflictos: el tercero que lo resuelve no debe decidirlo considerando todos los aspectos que son normativamente relevantes. Él debe considerar

\footnotetext{
${ }^{14}$ Locke, Dos Ensayos 211 (Segundo Ensayo, §13).

${ }^{15}$ Aquí vuelvo sobre un tema ya tratado en Atria, "Legalismo y reflexividad".

${ }^{16}$ Esto permite vadear lo que Detmold llama el 'vacío de particularidad' (particularity void). Véase Detmold, "Law as Practical Reason".

${ }^{17}$ A veces las reglas son extrañas, o a veces las reglas comunes a las partes no son suficientes para solucionar el conflicto. Estos casos crean problemas especiales de legitimidad de la decisión judicial, pero no afectan el argumento del texto principal, porque estos son casos en que algo no es como idealmente debe ser, son por eso casos patológicos.

${ }^{18}$ Véase Atria, 'Legislación y Jurisdicción' (MS en poder del autor)
} 
sólo una parcela de ellos, los que el derecho no excluye ${ }^{19}$. Así, por ejemplo, sus ideas sobre la justicia de la conmutatividad, y la equivalencia entre las prestaciones de comprador y vendedor no son, salvo en casos especiales, relevantes para decidir. El juez debe decidir conforme a reglas públicas, que son las que eran comunes a las partes. El juez no debe decidir de acuerdo a lo que le parece substantivamente correcto o justo.

Cuando las partes llevan su conflicto al juez no se están sometiendo a una especie de justicia del $\mathrm{Cadi}^{20}$. El juez no debe decidir el caso de acuerdo a lo que es (a su juicio) no-contingentemente justo, sino de acuerdo a lo que el derecho dispone. Y el juez puede adoptar la perspectiva del derecho simplemente porque sabe derecho y sabe ser juez. 'Saber derecho' significa manejar un canon especial de argumentación, i.e. saber identificar y evaluar la fuerza de un argumento que 'cuenta como' jurídico. Aquí yace toda la pretensión de autoridad que el juez y, a través de él, el derecho exhiben frente a las partes: en que la solución al conflicto entre ellas será una solución ofrecida desde el punto de vista jurídico, no sobre la base de lo que podríamos llamar 'argumentación práctica general'. Resolver en derecho no es lo mismo, no puede ser lo mismo, que resolver en justicia. Si resolver en derecho y resolver en justicia fueran lo mismo, entonces comprador y vendedor estarían en desacuerdo no sólo en cuanto a qué debe hacer cada uno de ellos, sino también en cuanto a ante qué juez llevar el caso. Es por eso que, en principio, la persona del juez resulta irrelevante para las partes ${ }^{21}$.

\footnotetext{
${ }^{19}$ Véase Atria, "Ubi ius, ibi remedium".

${ }^{20}$ La expresión es de Weber, Economy and Society 976-978.

${ }^{21}$ La controversia sobre el pez espada, entre Chile y la Unión Europea, es un buen ejemplo de esto: Invocando las normas de la Convención de Naciones Unidas sobre Derecho del Mar (Convemar) que permiten a los estados ribereños adoptar medidas tendientes a la conservación y explotación sostenible de los recursos marítimos, Chile decidió imponer ciertas restricciones a la extracción de pez espada en lo que éste denomina 'mar presencial', que de acuerdo a esa convención es alta mar. Por supuesto, Chile no se arroga derechos de policía sobre la alta mar; sólo prohíbe a los barcos pesqueros que violen las regulaciones sobre el uso de puertos chilenos. La Unión Europea, invocando los artículos V y XI del GATT, respondió solicitando la formación de un panel bajo los auspicios de la Organización Mundial del Comercio, para que éste declarara que Chile había infringido las obligaciones que había asumido bajo el GATT. Chile entonces recurrió al Tribunal Internacional de Derecho del Mar, el órgano encargado de la aplicación de la Convemar, para que éste declarara que la Unión Europea había violado su obligación, especialmente bajo el art. 64 de dicho tratado, de cooperar "con miras a asegurar la conservación y promover el objetivo de la utilización óptima de dichas especies [altamente migratorias] en toda la región, tanto dentro como fuera de la zona económica exclusiva". Por ahora los dos procedimientos están detenidos, porque las partes han llegado a un acuerdo preliminar. Pero el problema que plantea esta duplicidad de foros es importante, e ilustra la tesis del texto principal: en la medida en que las partes entiendan que los jueces aplicarán diversas normas sustantivas, o que la manera en que aplicarán las normas (aun siendo éstas las mismas) será sensible al tipo de jueces que son, entonces la controversia sobre el derecho de Chile a
} 


\section{El conflicto político}

¿Es asimilable el conflicto político al conflicto entre el comprador y el vendedor, que acabamos de considerar con cierta detención? Hans Kelsen, en su famosa polémica con Carl Schmitt, creía que sí, porque en definitiva el argumento central de Kelsen del control de constitucionalidad es el mismo que hemos dado antes para sujetar el conflicto entre comprador y vendedor al conocimiento de un juez:

$\mathrm{Si}$ algo es indudable es que ninguna otra instancia es menos idónea para [garantizar que los límites jurídicos no serían transgredidos]que aquélla, precisamente, a la que la constitución confiere el ejercicio total o parcial del poder y que, por ello, tiene en primer lugar la ocasión jurídica y el impulso político para violarla. Pues sobre ningún principio jurídico se puede estar tan de acuerdo como que: nadie puede ser juez de su propia causa ${ }^{22}$.

Tenemos dos tipos de razones para objetar este argumento. La primera, una de hecho (porque nótese que el argumento descansa sobre un supuesto de hecho, que el legislador se comportará como un comprador cuya obligación está sujeta a una condición meramemente potestativa que depende de su voluntad): no es verdad que los órganos políticos actúen como los individuos en el mercado, intentando maximizar su utilidad (en este caso su poder). Y de esto tenemos una muestra reciente: cuando uno mira la discusión que ha habido en la Comisión de Constitución, Legislación y Justicia del Senado con ocasión de las reformas constitucionales sobre justicia constitucional, uno puede ver el extraño espectáculo de parlamentarios enfrentados a ministros de la Corte Suprema y el Tribunal Constitucional. Mientras los primeros buscaban formas de limitar aun más sus propias atribuciones por la vía de crear una novedosa "acción de inconstitucionalidad", los segundos opinaban con una finalidad en mente: la de evitar cualquier recorte de sus competencia y beneficiarse de cualquier extensión de competencias que los senadores se manifestaban inclinados a discutir ${ }^{23}$. Al menos en este caso (y

imponer restricciones a la pesca de albacora en su mar presencial se reproducirá al momento de elegir el tribunal que ha de conocer del litigio. Para Chile la controversia versa sobre la necesidad de conservación de una 'especia altamente migratoria'. Chile entonces lleva el caso a un tribunal ante al cual el argumento conservacionista tendrá más expectativas de ser exitoso. Para la Unión Europea la controversia es una sobre libre comercio y restricciones unilateralmente impuestas. La Unión Europea, entonces, lleva el caso a un tribunal ante el cual la protección del libre comercio tiene más probabilidades de pesar como un argumento exitoso. Es el mismo conflicto, no uno distinto. Sobre este problema, véase Hervé y Fuentes, "La controversia del pez espada"; véase también Boyle, "The World Trade Organization and Maritime Environment".

${ }^{22}$ Kelsen, Quien debe ser 5.

${ }^{23}$ Véase Boletines NN $N^{\mathrm{o}} 2.526-07$ y 2.534-07 (6 de Noviembre de 2001), pp. 506-510; al respecto véase Atria, "Legalismo y reflexividad". 
creo que esto es generalizable) no ha sido el Congreso sino los tribunales (constitucional y Corte Suprema) los que han buscado, por la vía de la interpretación de las reglas que definen sus competencias o de la reforma constitucional, ampliar cada vez más sus atribuciones. Y estos tribunales también son jueces de su propia causa cuando el problema es el de delimitar la esfera de sus competencias.

Como ha sostenido M Tushnet, si los miembros del Congreso tienen un incentivo para maximizar la esfera de sus poderes y responsabilidades, lo mismo vale para la Corte Suprema respecto de $s u$ esfera. Y en Boerne ${ }^{24}$ la Corte ejerció tanto como pudo esa capacidad de maximizar su poder. Si la Corte es escéptica respecto de las decisiones que el Congreso toma al definir la esfera de sus poderes y responsabilidades, el Congreso y la ciudadanía deberían ser escépticas respecto de las decisiones de la Corte al definir -y maximizar- la esfera de sus poderes y responsabilidades ${ }^{25}$.

Pero esta no es la razón principal para objetar el argumento de Kelsen. Él suponía que el conflicto y su decisión debían ser caracterizados de modo análogo a nuestro caso de comprador y vendedor. Recuérdense esas características: (1) el conflicto surge no porque haya desacuerdo sobre las reglas abstractas, sino porque hay desacuerdo sobre cómo esas reglas abstractas definen las posiciones relativas de las partes en concreto; (2) la razón por la cual las partes están en desacuerdo es, al menos en una medida considerable, porque las personas tienden a ser más generosos con sus intereses que con los ajenos, particularmente cuando ellos están en contradicción; (3) las reglas a las que el juez debe recurrir para solucionar el problema no son ajenas a las partes; y (4) el juez debe decidir el problema no desde el punto de vista de su subjetividad, es decir, de sus concepciones del bien y el mal, la justicia y la conmutatividad, sino desde el punto de vista jurídico.

Me gustaría que resultara más bien natural ver a estas características en pares: porque (1) entonces (3), porque (2) entonces (4). Si tengo razón hasta aquí, ahora podemos ver claramente lo que estamos discutiendo en este panel: ¿se justifica la juridificación del conflicto político (o parte de él)? ¿Es razonable concebir al conflicto político, como Kelsen lo hizo, como un conflicto que responde a la descripción profunda del conflicto entre

${ }^{24}$ En City of Boerne v. Flores, 117 S Ct 2157 (1997) la Corte Suprema Norteamericana declaró inconstitucional la Religious Restoration Act 1993, a través de la cual el Congreso (en respuesta a Employment Division v Smith (494 US 872 (1990), en que la Corte sostuvo que los miembros de la Iglesia Nativa Americana que consumían peyote con fines sacramentales podían ser perseguidos criminalmente de acuerdo a la ley del estado de Oregón) pretendía interpretar las garantías constitucionales de igual tratamiento y debido proceso. La Corte sostuvo que esa pretensión violaba sus atribuciones exclusivas.

${ }^{25}$ Tushnet, Taking the Constitution away from the Courts, 26. 
comprador y vendedor? Para que los profesores de derecho constitucional, siempre listos para reclamar de la aplicación de criterios de 'derecho privado' a cuestiones constitucionales, no objeten esta formulación, o para que no crean ustedes que estoy siendo tendencioso al poner el tema de esta manera, déjenme explicitar qué quiero decir con 'sentido profundo': ¿es adecuado concebir el conflicto político como un conflicto cuya solución reside en encontrar reglas comunes y que pueda ser solucionado utilizando una forma de razonamiento que no depende de la subjetividad de quien decide, sino se puede resolver desde el punto de vista de esas reglas comunes? En la segunda parte de mi exposición quiero explicar por qué la respuesta a esta pregunta es negativa. Antes de eso, sin embargo, aclarar un punto preliminar, sobre el que volveré al final.

El lector podrá haber notado que no se trata de si el conflicto político es como el conflicto entre comprador y vendedor, sino si es adecuado concebirlo así. La diferencia entre las formulaciones es crucial, porque la política (o lo político) no es una cosa que pueda ser descrita desde fuera, de modo que la mejor teoría será la que mejor la describa. En este sentido, la política (como el derecho) no es como el movimiento de los cuerpos celestes y la evolución de las especies. Nuestras prácticas sociales, la política en particular, son prácticas constituidas por nuestras descripciones (al menos hasta cierto punto ${ }^{26}$. Si en un sistema jurídico determinado los seguidores de Oliver W. Holmes convencieran a todos los abogados y jueces de que el derecho es sólo un conjunto de profecías acerca de lo que los tribunales harán, entonces en esa jurisdicción el derecho efectivamente será un conjunto de tales profecías. Si un partidario de la escuela del public choice nos convenciera a todos de que los agentes políticos se comportan con la misma racionalidad que los agentes de mercado, entonces en nuestra práctica política los agentes políticos se comportarán efectivamente como agentes de mercado. Si todos nosotros nos convencemos de que el conflicto político es análogo al conflicto entre comprador y vendedor, entonces será análogo. La adecuación de la práctica a la teoría no demuestra la corrección de la teoría, sino sólo que ésta ha sido suficientemente influyente. Nótese la importancia de este punto: para decidir una cuestión sobre estas prácticas (parcialmente) constituidas por nuestras descripciones no podemos hacer lo que hacemos cuando queremos decidir (o mejor, en este caso: verificar) si la mecánica

\footnotetext{
${ }^{26}$ Esto no es una característica metafísica de las prácticas sociales (por eso la referencia a 'nuestras' prácticas sociales más que a 'las' prácticas sociales). Nuestras prácticas sociales son, en algún sentido, auto-concientes: no sólo tenemos prácticas (e.g.) políticas y jurídicas, sino que somos concientes de que tenemos esas prácticas como prácticas diferenciadas. Reflexionamos y discutimos sobre la política y el derecho. La diferenciación y auto-conciencia de nuestras prácticas es lo que las hace dependientes de nuestras teorías.
} 
de Newton es una teoría adecuada de la gravitación universal: no nos sirve observar la cosa objeto de la descripción y ver si ésta es correctamente descrita, porque ahora la cosa no existe con prescindencia de nuestras descripciones. Tratándose de estas prácticas, la determinación de lo que cuenta como una concepción adecuada (no verdadera) en algún momento debe hacer referencia a cómo sería bueno que fuera lo que estamos 'describiendo'. Creer que estamos describiendo algo que existe con prescindencia de nuestras descripciones cuando en realidad lo que estamos haciendo es (al menos parcialmente) constituir lo que estamos describiendo es lo que desde Marx podemos llamar falsa conciencia.

Ahora es necesario volver al argumento del penúltimo párrafo. Recuerden nuestras dos preguntas: (1) ¿Hay reglas comunes a las partes del conflicto cuya aplicación imparcial lo resuelva? (2) Hay una manera de resolver el conflicto que no dependa de la subjetividad del que decide? A la primera pregunta la respuesta natural es: si las hay, son los derechos fundamentales. A la segunda es: si la hay, es el derecho (constitucional). Ahora, en consecuencia, debemos hablar de los derechos fundamentales y del derecho constitucional, aunque veremos que en definitiva el tema es reconducible a uno: el de la distinción entre el razonamiento práctico general y una forma especial del mismo, el razonamiento jurídico.

\section{Derechos Fundamentales}

Los derechos fundamentales son el candidato obvio para cumplir la función de constituir las 'normas propias' de las que hemos hablado. Basta mirar la mayoría de las constituciones contemporáneas para notar que en ellas la idea de derechos fundamentales tiene una función estrictamente constitucional, constituyente. Ya lo decían los revolucionarios norteamericanos en 1776: "Sostenemos como verdades auto-evidentes" que los hombres nacen dotados de ciertos derechos. Precisamente en la idea de auto-evidencia es donde aparece la dimensión constitutiva de los derechos, porque las verdades 'auto-evidentes' no son aceptadas como verdades porque sean redimidas a través de la deliberación pública ${ }^{27}$. Al contrario, ellas fijan las condiciones bajo las cuales el conflicto es político y no (abierta o solapadamente) militar. Así como los norteamericanos creían en esas verdades auto-evidentes, nosotros, dice el argumento, creemos en los derechos "asegurados" por el artículo 19. En este sentido, entonces, los derechos del artículo 19 son 'nuestras' reglas, 'nuestras' en el sentido de que ellos nos constituyen a nosotros, los chilenos (aquí, pero sólo ad arguendo, me sumo a la aparente amnesia

${ }^{27}$ El tema es discutido, con referencia a la idea de derechos humanos, en Atria, "La hora del derecho" (de próxima aparición en Estudios Públicos). 
colectiva que afecta a los constitucionalistas chilenos sobre el origen de la constitución de 1980).

Sin embargo, las disposiciones del artículo 19 no son normas que satisfagan los requisitos propios de una norma jurídica. Y no los satisfacen no porque sean normas incorrectas, es decir injustas (aunque algunos por cierto lo son), sino porque ellas no expresan concepciones sino conceptos $^{28}$. Un concepto de justicia, por ejemplo, es el de Ulpiano, 'dar a cada uno lo suyo' (D 1.1.10). En este sentido, un concepto es una formulación muy abstracta del contenido de una idea. Un concepto no es una tautología (la tesis de Ulpiano puede ser negada sin contradicción) pero su nivel de abstracción lo hace políticamente incontrovertido. Las personas con concepciones opuestas de la justicia no necesitan discutir el concepto de justicia, pueden reservarse su batería de argumentos para las controversias que surgirán al momento de intentar especificar el contenido del concepto, en este caso al intentar especificar qué es lo que cada uno puede reclamar como suyo ${ }^{29}$. Esta ulterior especificación es lo que constituye una concepción.

No estoy sosteniendo que los conceptos son vacíos o políticamente inútiles. Al contrario, los conceptos nos permiten entender el rol constitutivo de los derechos. Así entendida, una comunidad política se define por el consenso sobre los conceptos: es correcto dar a cada uno lo suyo (justicia), tratar a todos con igual consideración (igualdad), ordenar las interacciones sociales de modo que cada uno pueda vivir como es bueno para ellos vivir (libertad). La consecuencia de esto, sin embargo, es que los conceptos no aparecen en propia persona en el conflicto político normal: el conflicto político normal es el conflicto sobre cómo hemos de entender nuestros conceptos comunes (es decir, sobre concepciones).

Por lo anterior, la apelación a un concepto (como los derechos fundamentales) nos permite responder sólo una de nuestras dos preguntas: si son normas comunes su aplicación imparcial no puede solucionar el conflicto; si su aplicación imparcial puede solucionar el conflicto no son normas comunes. Ante un conflicto sobre la justicia podemos efectivamente decir que hay un 'estándar común' constituido por el concepto de justicia, pero es un estándar que es inútil para dirimir nuestro conflicto. Norberto Bobbio, por ejemplo, ha notado esto en su intento de distinguir derecha e izquierda. Como se sabe, él cree que la distinción está en las concepciones de la igualdad de cada una de estas posiciones, pero no se encuentra, la diferencia, en los

${ }^{28}$ La distinción entre conceptos y concepciones fue formulada originalmente por Hart, Concept of Law, y fue luego utilizada por Rawls, Theory of Justice §1 (Rawls, Teoría 1) y por Dworkin, Law's Empire 71-72 (Dworkin, El Imperio de la Justicia 60-61).

${ }^{29}$ Esto ya lo había notado, entre otros, Kelsen, ¿Qué es la Justicia? 67-68. 
conceptos de igualdad, en el hecho de que sólo una de las partes encuentre en la igualdad algo valioso. Como ha dicho Norberto Bobbio, “qué doctrina política no tiene que ver en mayor o menor medida con la igualdad?"30.

Lo que aquí Bobbio está diciendo es que a pesar de que las concepciones sobre la igualdad son las que distinguen derecha de izquierda, o mejor dicho precisamente por eso, no podemos usar la idea (o concepto) de igualdad para decidir un conflicto entre derecha e izquierda. Ambas partes aceptan el concepto de igualdad (es decir: ambas partes creen que la igualdad es importante, pero aun así están en desacuerdo sobre qué cuenta como 'igualitario'). De nuevo: si hablamos de el concepto de igualdad, estamos haciendo referencia a una norma común a izquierda y derecha, pero a una norma cuya aplicación imparcial no puede solucionar el conflicto, precisamente por ser común; si lo soluciona, entonces no estamos hablando de una norma común, sino de una concepción (de izquierda o derecha) de la igualdad.

$\mathrm{Si}$ los derechos constitucionales expresan conceptos, entonces, ellos son efectivamente 'normas comunes', pero son normas cuya aplicación no adjudica el conflicto. Para adjudicar el conflicto los conceptos que aparecen en el art. 19 de la constitución deben ser complementados por una concepción de esos derechos. Pero esa concepción no está en la constitución, porque la constitución es (o debe ser) neutral entre las diversas concepciones (precisamente porque es, o debe ser, 'nuestra', común). Por lo tanto, si utilizamos la aplicación judicial de la constitución para dirimir el conflicto político, entonces estamos exigiendo al juez que complemente el contenido del art. 19 con su propia concepción de los derechos fundamentales. Pero entonces el juez deja de ser un tercero imparcial, cuya neutralidad respecto del conflicto de las partes era, recuérdese, la mejor garantía de que su juicio sería correcto. Ahora sí nos importa si el juez es socialista o liberal, y con esto violamos la segunda condición establecida al principio: no hay manera "jurídica" de decidir estos conflictos que no sea una reproducción del conflicto político. El juez puede seguir llamándose juez, pero ahora es un aliado de una de las partes. Es un activista (liberal, conservador o socialista, etc.) disfrazado de juez.

\section{Razonamiento jurídico}

El argumento, entonces, nos ha llevado al segundo problema. Hemos encontrado 'normas comunes' para las partes de un conflicto político, pero son normas que no pueden ser suficientes para solucionar el conflicto. Esto nos lleva a cuestionar la plausibilidad de la segunda condición indicada al principio, esto es, que solucionar el caso ‘jurídicamente' no es lo mismo que

\footnotetext{
${ }^{30}$ Bobbio, Derecha e Izquierda, 141.
} 
solucionarlo 'políticamente'. La idea aquí es que el razonamiento jurídico no es simplemente el razonamiento político o moral conducido por alguien a quien una norma jurídica llama "juez", sino es un razonamiento de tipo distinto.

Nótese la importancia de esta condición: imaginen un conflicto sobre la igualdad entre personas sosteniendo concepciones socialistas y liberales de la igualdad. ¿Qué razón podría tener el liberal para creer que la manera adecuada de solucionar el conflicto es llevar el problema ante un juez socialista? La única razón que puede tener (aparte de su deseo de rendirse) es su creencia de que el juez, antes que solucionar el caso como socialista, lo hará como juez. Pero esto supone que el caso de que se trata puede ser solucionado por una persona como juez y no como socialista o liberal, y eso es lo que quiero discutir aquí.

En la sección anterior hemos encontrado razones para pensar que esto es imposible: el artículo 19 contiene una lista de conceptos políticos, y los conceptos políticos no discriminan entre posiciones políticas normales, a menos que sean complementados por concepciones. Pero las concepciones son lo que anima la deliberación y el conflicto político, por lo que el juez sólo podrá solucionar el conflicto si se adhiere a una concepción (socialista, liberal u otra). Y ¿cuál será la concepción a la que el juez adherirá? Respuesta obvia: la que el juez crea correcta. El socialista adherirá a una concepción socialista, el liberal a una concepción liberal, etc. Cuando se trata de aplicar el art. 19 de la constitución, no hay, no puede haber, distinción entre el razonamiento jurídico y político.

Mi impresión, sin embargo, es que este argumento no exhibe toda su fuerza cuando es presentado en abstracto. Por eso es conveniente ofrecer ahora una demostración ejemplar de qué es lo que quiero decir cuando digo que tratándose del artículo 19 no puede haber diferencia entre el razonamiento jurídico y el político. Para eso, en lo que sigue quiero primero exponer un caso de conflicto político sobre los derechos y luego considerar diversas maneras en que ese ejemplo podría intentar ser respondido por quien quisiera defender la distinción, a este nivel, entre lo jurídico y lo político, para que podamos ver cómo estas estrategias fallan.

El ejemplo que quiero discutir es el siguiente: yo estoy convencido (aunque no puedo ofrecer el argumento aquí) que un compromiso verdadero con la igualdad exige, inter alia, la creación de un sistema de salud universal, gratuito al momento de uso, combinado con (a) impuestos progresivos y (b) regulaciones que hagan imposible o a lo menos disuasivamente caro para los ricos excluirse y contratar seguros privados. No hay otro modo, creo, de asegurar igualdad en el suministro de asistencia médica. Ahora, puede que me equivoque porque me falta alguna información empírica. Quizás 
simplemente no sé lo suficiente sobre los méritos comparativos del sistema chileno de IISAPRE ${ }^{31}$ frente a un sistema de salud financiado públicamente independiente del nivel de ingresos de los individuos (en adelante, servicio nacional de salud, o SNS). Es más, podría estar equivocado en otro sentido, si la igualdad pudiera en los hechos ser asegurada por un sistema de seguros de salud privados, es decir, si mi teoría sobre la igualdad como valor político fuera incorrecta. Pero éste no es el punto aquí, porque seguiré creyendo lo que creo ahora hasta ser convencido de lo contrario, porque uno sólo puede creer lo que cree (en todo caso, el que ésta sea la idea que inspira al llamado 'estado de bienestar' europeo la dota, al menos, de plausibilidad inicial) ${ }^{32}$.

El problema que quiero discutir ahora es: ¿qué se supone que debo decidir si un reclamo sobre la constitucionalidad de la ley que regula las IISAPRE en Chile debe ser dirimida por la corte constitucional de la que formo parte?

Permítaseme primero definir las reglas del juego: tanto el derecho a la igualdad (arts. $1^{\circ}, 19 \mathrm{~N}^{\circ} 2$ ) como el derecho a la "protección de la salud" $\left(19 \mathrm{~N}^{\circ}\right.$ 9) son mencionados por la constitución chilena como parte de los llamados 'derechos constitucionales'. Ambos parecen poderosos candidatos a ser fundamentales, por lo menos tan poderosos como cualquier otro. Si los derechos fundamentales constituyen 'límites a las decisiones mayoritarias' y si yo verdadera y honestamente creo que un seguro privado sumado a subsidios estatales basados en el ingreso va a producir desigualdad, entonces no veo cómo puedo evitar la conclusión de que mi deber como guardián de la constitución y los derechos fundamentales es declarar inconstitucional la ley de IISAPRE. Considero, sin embargo, esta conclusión como una reductio ad absurdum: si la corte constitucional puede elegir el sistema de salud para un país como Chile, no veo por qué no debería decidir sobre la tasa adecuada del impuesto a la renta, la manera preferible de combatir la delincuencia, la lista de conductas que debe ser penalmente típica, etc.

Éste es, entonces, nuestro problema: si he de aplicar los conceptos constitucionales del art. 19 a controversias políticas tendré que complementar esos conceptos con alguna concepción, y naturalmente no podré hacerlo sino con la concepción que es a mi (falible) juicio correcta (lo contrario sería prevaricación). Pero mi concepción sobre la igualdad o la protección

${ }^{31}$ ISAPRE $(p l$ IISAPRE)=Institución de Salud Previsional (agencia privada de seguros de salud).

${ }^{32} \mathrm{NB}$ : Que uno sólo pueda creer lo que cree no quiere decir, desde luego, que uno no pueda cambiar sus creencias. Pero el converso que recuerda sus días agnósticos entenderá que entonces estaba equivocado (no sólo que ahora estaría equivocado si siguiera creyendo lo mismo), y eso no cambiará por el hecho de que si en esos días le hubieran preguntado su opinión acerca de los creyentes también habría respondido que ellos están equivocados. 
de la salud o la libertad es suficiente para dirimir prácticamente todos los conflictos políticos, como supongo que le ocurre al lector también: uno tiene opiniones sobre la igualdad, la libertad, la protección de la salud, etc, que justifican sus opiniones políticas sobre la mayoría de los temas políticos que se discuten. De las opiniones de cada uno sobre la igualdad, la libertad, el debido proceso (etc), se sigue una opinión sobre el problema de la inmigración, la utilización de cámaras de velocidad en las carreteras, la anticoncepción de emergencia, el llamado 'problema de los derechos humanos' en Chile, etc. Si el deber de un miembro de un tribunal constitucional es complementar los conceptos constitucionales de igualdad y libertad (etc) con sus propias concepciones, entonces todos los conflictos políticos son solucionados por la constitución así complementada. Podemos prescindir del parlamento y pedirle a los miembros del tribunal constitucional que tomen las decisiones por nosotros.

Como dije, creo que esto es una reductio ad absurdum, es decir, creo que quien quiera defender la aplicación judicial de la constitución a conflictos políticos deben evitar esta conclusión. De modo que veamos cómo es posible evitarla:

Primero. Se ha dicho que no se llega a la situación en la que el tribunal constitucional reemplaza al Parlamento, porque este tribunal es un 'legislador negativo' ${ }^{33}$. No tiene iniciativa para decidir, sino sólo para vetar. Pero esta limitación, aunque soluciona parte del problema, deja abierto el problema principal, porque yo puedo estar convencido de que sólo tengo autoridad como legislador negativo y aun así revocar la ley de IISAPRE: todo lo que tendría que concluir es que no puedo instruir al legislador a crear un SNS, pero eso me dejaría en libertad para declarar inconstitucional toda otra alternativa hasta que el legislador le 'acierte'.

Segundo. Algunos autores han creído que el problema que estamos discutiendo es una peculiaridad de los llamados derechos 'sociales' que no se presenta respecto de los derechos llamados 'civiles y políticos'. Ellos explican esta diferencia porque éstos son negativos en el sentido de que sólo exigen una abstención, mientras aquellos son positivos porque demandan una acción ${ }^{34}$. Si esto fuera correcto, la solución a nuestro problema podría ser la de restringir el rango de los derechos judicialmente protegibles, y limitarlo a los llamados derechos 'negativos'. Pero esto tampoco funciona, porque el argumento de nuestro ejemplo no es que el gobierno, al modificar la ley de IISAPRE, está dejando de hacer algo (aunque también creo es-

${ }^{33}$ Cf. Kelsen, ¿Quién Debe Ser el Defensor de la Constitución? (Madrid: Tecnos, 1995; orig edn 1931), pp. 36-37.

${ }^{34}$ He discutido esta cuestión en Atria, “Existen derechos sociales?”. 
to), sino que está activamente haciendo algo que implicará un tratamiento desigual, algo que llevará, como ha llevado en Chile, a la existencia de dos países: uno donde la gente va a la consulta y luego a la clínica, antes de ir a dejar a los niños al colegio, y otro donde uno va primero al consultorio y luego al hospital, antes de recoger a los niños de la escuela (todo esto complementado con un derecho a la igual libertad de ricos y pobres no sólo para dormir bajo los puentes del Mapocho, sino también para elegir entre escuelas y colegios, consultas y consultorios, hospitales y clínicas). De aquí que un derecho negativo, que proteja a los ciudadanos de cualquier acto gubernamental que niegue su igualdad justificaría, bajo los supuestos descritos aquí, que yo revoque la ley de IISAPRE por inconstitucional, y por consiguiente no nos permitiría evitar la conclusión absurda de que es el tribunal constitucional el que tiene potestad para decidir todas las cuestiones relevantes políticamente ${ }^{35}$.

Tercero. Una distinción relacionada que podría usarse aquí (o quizás la misma distinción bajo distintas etiquetas) es la que distingue entre derechos de 'libertad' y de 'bienestar'36, derechos que sólo pueden ser respectados actuando de un modo determinado y derechos que pueden ser satisfechos de varias maneras alternativas. R Alexy ha sostenido que los derechos 'de libertad' corresponden a la primera descripción mientras los derechos 'de bienestar' corresponden a la segunda. Así las cosas, mi deber como magistrado constitucional de no revocar la ley de IISAPRE por inconstitucional nacería del reconocimiento de que, como hay más de una forma de respetar y promover esos derechos de 'bienestar', debería reconocérsele al poder legislativo un 'margen de acción'. Alexy explica esta idea de la siguiente manera:

\footnotetext{
${ }^{35}$ Otra manera de mostrar que la distinción entre derechos positivos y negativos no puede cumplir la función de distinguir entre derechos-como-límite y otros derechos es ésta: en la noche del 22 de abril de 1993 un adolescente negro, Stephen Lawrence, fue apuñalado hasta la muerte en Londres. La policía no presentó cargos contra quienes eran considerados como los principales sospechosos del crimen, un grupo de adolescentes blancos. Después de una investigación pública y dos conducidas por la policía se llegó a la conclusión de que la Policía Metropolitana actuaba con considerable racismo conciente e inconsciente. La investigación pública, conducida por Sir William MacPherson, llegó a la conclusión de que la Policía Metropolitana demostraba considerable 'racismo institucional', i.e. "el fracaso colectivo de una organización de proveer un servicio apropiado y profesional a las personas en razón de su raza, cultura, u origen étnico". El derecho a no ser discriminado por razones raciales es probablemente uno de los candidatos más obvios a ser un derecho-como-límite (negativo), y sin embargo en este caso para que el gobierno lo respetara no era suficiente que se abstuviera de hacer cosas: debía hacer, al contrario, un cantidad de cosas bastante caras para cambiar la cultura policial que fomentaba y mantenía ese racismo institucional.

36 'De bienestar' lo uso aquí como sinónimo de 'de prestación' (hay controversia sobre su propia denominación, por lo que aquí debe entenderse la anterior como una mera etiqueta).
} 
Si es posible salvar a alguien que se está ahogando o bien nadando o bien arrojándole un salvavidas o con la ayuda de un bote, en modo alguno están ordenadas al mismo tiempo las tres acciones de salvamento. Lo que está ordenado es, más bien, la realización de la primera, de la segunda $o$ de la tercera acción. Pero esto significa que el destinatario del mandato de salvamento, si no se suman otras razones limitantes, tiene un campo de acción dentro del cual puede elegir cómo desea cumplir con el mandato. Con la expresión 'campo de acción' se ha pronunciado la frase clave con respecto a la justicialidad de los derechos a acciones positivas ${ }^{37}$.

El problema con esta explicación es que contiene una petición de principios. Ciertamente yo podría creer que tanto un SNS como un sistema de IISAPRE son igualmente adecuados para proteger el derecho la igual protección de la salud, pero esto no es lo que creo. De hecho, la mayoría de los partidarios de ambos sistemas estarían en desacuerdo con esta afirmación. ¿Desde dónde opina el abogado de Alexy cuando sostiene que ambas formas son igualmente adecuadas? Esto parece ser simplemente una tercera posición, pero Alexy cree que puede formularla desde un punto arquimedeano, neutral entre ellas. Sólo concibiéndola así podemos usar esta tercera postura para decidir si el conflicto entre las otras dos es constitucionalmente aceptable, para decidir si el legislador tiene un 'campo de acción' constitucionalmente protegido. Pero este punto arquimedeano no existe, y esta posición, la que sostiene que ambos sistemas son 'constitucionalmente equivalentes' y por eso que el legislador tiene un 'campo de acción', el mismo campo de acción que tiene la persona que debe salvar al que se está ahogando arrojándole un salvavidas o nadando hacia ella, es simplemente una tercera posición. Ahora en nuestro ejemplo debemos tomar en cuenta tres posiciones, no dos: (1) al que cree que sólo un sistema público con restricciones al seguro privado logra proteger igualitariamente la salud; (2) al que cree que sólo un sistema de seguros privados (con subsidios para los que no pueden pagarlos) es aceptable por consideraciones de libertad personal, y (3) la de Alexy, que sostiene ambas fórmulas proveen de la misma protección. Pero la posición (3) es una concepción de los derechos en cuestión que no se distingue cualitativamente de las otras. Alexy sólo ha mostrado que si uno cree que los dos sistemas son aceptables, entonces los dos sistemas son constitucionalmente aceptables. Pero la recomendación de Alexy al que cree en la posición (1) no soluciona nuestro problema:

Cuando son adecuadas varias acciones de protección o promoción, ninguna de ellas es necesaria para el cumplimiento del mandato de protección

\footnotetext{
${ }^{37}$ Alexy, Teoría de los Derechos Fundamentales (Madrid: Centro de Estudios Constitucionales, 1997; orig. ed. 1986) p. 447.
} 
o promoción; lo único que es necesario es que se realice alguna de ellas. Sólo si existe una única acción adecuada de protección o promoción, ella es necesaria para el cumplimiento del derecho a prestación. En este caso, la estructura del derecho a prestación es igual a la del derecho de defensa ${ }^{38}$.

El argumento de Alexy se basa en la distinción entre la pregunta política (¿cuál es el mejor sistema?) y la pregunta jurídica (¿cuáles son los sistemas aceptables constitucionalmente?). Pero estas dos no son cuestiones distintas: un socialdemócrata europeo creerá en (1), mientras lo que nosotros llamamos un 'liberal' creerá en (2), y lo que los norteamericanos llaman un 'liberal' creerá (3). Alexy arbitrariamente concede a (3) una posición de preferencia, de árbitro. Me sorprendería mucho si en su calidad de ciudadano Alexy no pensara que la posición correcta es la (3).

Cuarto. La cuarta forma de evitar nuestra conclusión absurda, defendida por C. Rosencrantz ${ }^{39}$, soluciona el problema de raíz: ella afirma que, como hay desacuerdo político respecto de cuáles son los principios distributivos correctos, debemos excluir del catálogo constitucional referencia a los llamados 'derechos sociales'. Rosencrantz llega a la misma conclusión a la que ya habíamos llegado respecto de los que llama 'derechos distributivos', es decir, que no constituyen normas comunes a las partes cuya aplicación imparcial pueda solucionar el conflicto entre ellas. Pero él cree descubrir esas normas comunes en las que, siguiendo a Rawls, denomina 'libertades básicas ${ }^{40}$, y por eso afirma que ellas pueden ser constitucionalizadas sin detrimento del conflicto y la deliberación políticos. De este modo el profesor Rosencrantz cree poder evitar la conclusión absurda: el derecho a la protección de la salud no estaría constitucionalmente protegido, y por consiguiente la manera en que los servicios públicos o privados han de organizarse para proveer protección a la salud sería una cuestión que quedaría completamente entregada a la decisión legislativa. Pero lo que Rosencrantz no nota es que lo que él llama 'derechos distributivos' pueden afectar a las libertades básicas, al menos de acuerdo a algunas concepciones de éstas (y de aquellas). Así, por ejemplo, un sistema público y universal de salud sólo es sostenible en la medida en que se restringe el derecho de los usuarios de elegir el médico tratante. ¿Es esto una restricción a las libertades básicas protegidas por la constitución? O para considerar un caso más cercano a nuestra experiencia: el Gobierno chileno ha anunciado su intención de establecer la obligación de los colegios particulares subvencionados de recibir

\footnotetext{
${ }^{38}$ Idem, p. 47 (subrayado agregado). Alexy llama a veces 'derechos de defensa' a los 'derechos de libertad', pero estos términos son sinónimos (cf. idem, p. 419).

${ }^{39}$ Rosencrantz, "La pobreza, la ley y la constitución"

${ }^{40}$ Rawls, Theory of Justice (Rawls, Teoría §11).
} 
una cuota de $15 \%$ de lo que el Gobierno llama 'alumnos vulnerables', que los colegios subvencionados no podrían rechazar. Esta medida, podemos suponer aquí, pretende aumentar la integración y diversidad social de esos colegios y mejorar la educación a la que pueden acceder niños de condición 'socioeconómica y familiar' precaria. Los sostenedores ${ }^{41}$ de esos colegios probablemente reclamarán que esta restricción a su libertad es inconstitucional, y ese reclamo llegará a una corte ${ }^{42}$. La corte, por su parte, notará que lo que el Gobierno busca no es, en términos de Rosencrantz, promover una 'libertad básica', sino un objetivo agregativo (disminuir la desigualdad del sistema educacional, o aumentar las oportunidades de los niños más 'vulnerables'). No es posible determinar la constitucionalidad de esta medida sin una concepción política que asigne peso relativo a la libertad del dueño de un colegio subvencionado de elegir a los alumnos de éste y a la igualdad de oportunidades (o la finalidad que a su juicio esté detrás de la iniciativa de Gobierno $)^{43}$.

${ }^{41}$ En Chile hay establecimientos educacionales (básicos y secundarios) de tres regímenes: municipales, privados subvencionados y privados. Los últimos son establecimientos que se financian exclusivamente con lo que perciben de sus alumnos como pago de la educación que reciben. Los dos primeros son financiados por el Estado. Los establecimientos municipales son además gestionados por el Estado, a través de los municipios. Los privados subvencionados pertenecen a una persona natural o jurídica (un 'sostenedor') que recibe una subvención por alumno. El sostenedor de un establecimiento subvencionado lo administra y tiene una libertad bastante amplia para decidir cuestiones sustantivas como admisión, filiación religiosa del establecimiento (muchos de estos colegios subvencionados pertenecen a la Iglesia Católica y son colegios de denominación católica), reglamento interno (incluyendo causales de expulsión), etc.

${ }^{42}$ Como ya han reclamado algunos profesores: véase Sierra, "Cuotas obligatorias".

${ }^{43}$ Otra instancia del mismo problema: En Chile, toda persona que recibe una remuneración como trabajador dependiente está por ley obligada a destinar el 7\% de ella (con un tope superior) a pagar por un plan de salud. Si esa cantidad es suficiente, la persona contrata un seguro privado de salud con una ISAPRE; si no lo es, la persona es cubierta por FONASA (=Fondo Nacional de Salud), el sistema público, y su 7\% es percibido por FONASA. Como parte de una reforma de los sistemas de protección de la salud, el Gobierno ha propuesto que en todo caso una parte de este 7\% se destine a FONASA. Así, parte de lo que hasta hoy es una cotización obligatoria pasaría a ser un impuesto. Con el resto las personas todavía podrán hacer lo que deseen: contratar un seguro en una ISAPRE o recurrir a FONASA. Huelga decir cuál será la consecuencia de esta reforma, si llega a realizarse: muchas personas que hoy están en condiciones de pagar un seguro privado no podrán hacerlo y tendrán que retirarse del sistema privado para recurrir al público. ¿Es esto constitucionalmente aceptable? Para los que creen que (1) es la respuesta correcta, ésta puede ser una medida transicional adecuada; quienes creen (2) creerán que es inaceptable. De hecho, un miembro del tribunal constitucional chileno que es partidario de (2) ya ha hecho saber su opinión: "el 7\% de cotización obligatoria impuesta por la ley es patrimonio del cotizante respectivo, estando destinada [sic] a contribuir al financiamiento de las acciones de salud para él y sus familiares. Se trata por consiguiente y sin duda, de un bien cuyo dominio o propiedad pertenece al cotizante. Por tal razón consideramos discutible el mérito constitucional de la idea, hasta hoy sólo tal y no articulada en proyecto de ley, que destina el 3\% de ese guarismo a un fondo común y solidario para el propósito referido" (Cea, Derecho Constitucional Chileno 312). 
Pero se nos ha dicho que los derechos (al menos los 'de libertad') son protecciones contra-mayoritarias, "cartas de triunfo" 44 , queriendo decir con eso que los derechos no pueden ser 'sopesados' cuando entran en conflicto con finalidades agregativas, es decir, de bienestar colectivo. En nuestros ejemplos, sin embargo, parece que hemos llegando precisamente a la conclusión de que el juez constitucional deberá sopesar derechos contra finalidades colectivas. Para evitar esta conclusión, deberíamos volver sobre nuestros pasos, desechar el argumento del párrafo anterior y negarle al juez constitucional potestad para balancear la libertad del sostenedor de un colegio subvencionado de elegir a los alumnos de éste con la igualdad de oportunidades. El juez tiene que declarar inmediatamente la inconstitucionalidad del proyecto mencionado porque, con independencia de cuánto bienestar colectivo ellas podrían originar, lo hacen restringiendo libertades, y los derechos nunca pueden ser restringidos para aumentar la utilidad global.

De modo que enfrentamos una alternativa, a pesar de que para evitar alternativas como éstas ya hemos pagado el precio increíblemente alto de eliminar de nuestra constitución toda referencia a los 'derechos sociales': o instruimos a nuestros jueces para que entiendan las libertades básicas como 'cartas de triunfo', declarando inconstitucional cualquier medida que, para obtener una finalidad agregativa, afecte a una de esas libertades, o los instruimos para que cuando una finalidad colectiva afecte una libertad básica sopesen los valores relativos de una y otra; consideren el valor de la libertad que se ve afectada en relación al valor del fin agregativo que la medida en cuestión persigue. Si elegimos el primer camino, estaremos dando prioridad completa a las libertades básicas sobre las demandas de justicia distributiva, constitucionalizando un régimen neoliberal nozickeano ${ }^{45}$; en el segundo, estaremos volviendo a nuestro problema original, porque para decidir cuál es el peso relativo de las distintas políticas de gobierno tenemos precisamente al parlamento ${ }^{46}$.

${ }^{44}$ Dworkin, "Rights as Trumps".

${ }^{45}$ La referencia es a Nozick, Anarquía.

${ }^{46}$ En conversación, el profesor Rosencrantz ha manifestado que el argumento anterior no lo representa fielmente. Él no constitucionalizaría una garantía de libertad en sentido amplio, precisamente para evitar el problema al que me he referido. La lista de derechos constitucionales que Rosencrantz incluiría en la constitución resulta ser particularmente restringida, y sólo se referiría, podemos suponer, a aquellos derechos en contra de cuya violación "todos reaccionarían instantáneamente". Rosencrantz, "La pobreza, la ley y la constitución", 249. A mi juicio, con esta solución Rosencrantz soluciona nuestro problema, pero al precio de reducir nuestras normas comunes a un mínimo extraordinariamente reducido. Como se verá, mi respuesta es que incluir conceptos en la constitución tiene una función constitutiva importante, y no veo, como Rosencrantz, razón para entender que nuestras normas comunes deben ser interpretadas por otros: ¿por qué no podemos, como ciudadanos, reclamar para nosotros la competencia de 
$\mathrm{Y}$ ahora completemos el círculo, antes de volver al punto inicial. Hemos visto que en definitiva nos vemos enfrentados a la alternativa de entender que cuando la constitución protege libertades básicas las está convirtiendo en lo que los filósofos del derecho llaman razones excluyentes ${ }^{47}$, es decir, razones para decidir sin considerar el balance de (otras) razones, en particular sin considerar cómo la acción propuesta fomenta el bienestar colectivo, o concebirlos como razones de primer orden especialmente fuertes, que en consecuencia pueden ser derrotadas por otras razones de primer orden (como el bienestar colectivo que se seguirá de la adopción de determinada política). Enfrentados a esta cuestión ¿cómo hemos de decidir? La respuesta es previsible: no puede ser sino una cuestión de concepciones políticas. La primera posibilidad termina en un estado nozickeano, mínimo o ultramínimo, y no es raro que quienes tienen simpatías por el neoliberalismo de Anarquía, Estado y Utopía entenderán los derechos de esta manera, como Nozick, como restricciones morales indirectas ${ }^{48}$ (el libro de Nozick comienza diciendo "los individuos tienen derechos, y hay cosas que ninguna persona o grupo puede hacer sin violar esos derechos" ${ }^{\text {"49 }}$ ). La segunda, por su parte, hace constitucionalmente posible un estado más interventor, y por eso no es extraño que quienes se encuentran más cercanos a posiciones socialdemócratas o socialistas optan por la segunda opción. No es sólo el concepto de libertad o igualdad lo que requiere ser complementado por una concepción de la libertad y la igualdad. Es el concepto mismo de derecho el que no sirve si no es complementado por una concepción del mismo tipo.

\section{Conclusión. Política y derecho: todo es político}

En algún sentido esto nos enseña lo que ya sabemos. Todos nosotros tenemos creencias, más o menos fuertes, sobre el bien y la justicia, sobre cuáles son las decisiones políticas correctas y cuáles incorrectas. En clave de primera persona del singular, estas creencias no son contingentes: yo no puedo creer en una concepción de la justicia y al mismo tiempo creer que creo sólo porque decido creer. No, yo creo en lo que creo porque lo que creo es correcto ${ }^{50}$.

\footnotetext{
interpretar (a través de la acción política) nuestras normas comunes? He discutido el estatus de esta lista muy restringida de derechos extraordinariamente duros en Atria, "La hora del derecho", Atria, "Legalismo, política y derechos".

${ }^{47}$ Raz, Practical Reason and Norms 142.

${ }^{48}$ Nozick, Anarquía 40-47.

49 ibid 7.

${ }^{50}$ Esto lleva a interesantes paradojas tratándose de creencias que sabemos que tenemos por razones contingentes (como el que es católico pero sabe que si no hubiera nacido en una familia católica no lo sería): véase Cohen, Si Eres Igualitarista, ¿Cómo es que eres tan rico? 23-38.
} 
Las creencias que describimos en tercera persona, por otra parte, pueden ser concebidas como contingentes.

Aunque lo anterior puede parecer insostenible, en realidad es obvio, y para mostrar su obviedad podemos decirlo de otro modo: es perfectamente posible decir, en tercera persona, 'él cree que X (es correcto), pero está equivocado'; es contradictorio decir, en primera persona: 'yo creo que $\mathrm{X}$ (es correcto) pero estoy equivocado'. Por supuesto esto no implica que yo no pueda estar, de hecho, equivocado. Sólo implica que yo no puedo creer que $\mathrm{X}$ y al mismo tiempo creer que sería correcto que pensara de modo distinto. En este sentido yo no puedo concebir mis creencias morales como contingentes.

Pero las decisiones políticas que nosotros tomamos valen precisamente por razones contingentes, como por ejemplo que una mayoría las ha aprobado en las circunstancias tales y cuales. La democracia sólo es posible en la medida en que cada ciudadano acepte que sus opiniones, no contingentes como cada uno de ellos las entiende, carecen de cualquier preferencia especial: ellas valen tanto como las opiniones contingentes de los otros. Por esto, lo político empieza cuando ante el hecho del desacuerdo los miembros de una comunidad están dispuestos (al menos parte del tiempo) a ver sus creencias desde la perspectiva de la tercera persona, simplemente como creencias que pueden o no ser correctas. Esto no quiere decir falta de fidelidad a las creencias de uno, quiere decir que entre las creencias de uno está la creencia de que la existencia de la comunidad política hace posible una forma de vida que tiene valor aun a pesar de que ella a veces actúe de modo reprochable. Pero no hay garantía de que esto siempre va a ser así. El colapso de 1973 se debió a que una buena cantidad de chilenos creyeron que la supervivencia de la comunidad política chilena tenía menos valor que la justicia o injusticia intrínseca de esa práctica. Esta es probablemente una de las decisiones más profundas que una persona puede tomar, y para ella cada uno de nosotros está solo en el universo: ¿Es tu posición, con la que yo disiento, tan opuesta a mi forma de vida o a lo que yo creo que es correcto que nuestra común pertenencia a una comunidad política pierde su valor? ¿O es una que, aunque considero más o menos equivocada, no priva de valor a la comunidad que tu y yo compartimos? En el primer caso hemos llegado a los límites de lo político: más allá queda la guerra. Ese fue el punto que los chilenos alcanzamos hace 30 años. En el segundo caso nos reconocemos como ciudadanos iguales de una práctica política valiosa, y seremos adversarios políticos. Pero estas decisiones son nuestras, como ciudadanos, y no de jueces. En esto los jueces son, como hemos visto, simplemente otros ciudadanos.

Al nivel del que estamos hablando, todo es político y no podemos escaparnos de eso. No tiene sentido que, llenos de nostalgia por un premo- 
derno orden natural, no-contingente, busquemos anclar nuestras prácticas políticas en algo que no dependa de nuestras prácticas: sólo el Barón de Münchhausen puede salir del agua tomándose de los pelos y tirándose hacia arriba. Desde los inicios de la modernidad hemos entendido lo político como contingente, en el sentido de que podría haber sido de otro modo. Para bien o para mal, ya no podemos encontrar refugio ni en la naturaleza ni en la divina providencia, porque ni la naturaleza ni la divina providencia nos gobiernan: nosotros nos gobernamos, y sólo por eso podemos ser libres. La contingencia de la política es lo que hace posible la libertad. Pero la contingencia de la política aterra, en particular a comunidades políticas que han quedado traumatizadas, como la chilena, después de haber sufrido las consecuencias de esta contingencia, de que las cosas siempre puedan ser de otro modo, incluso del peor modo posible. Es entonces cuando oímos el canto de sirena del derecho, la promesa de que es posible encontrar algo no contingente, algo que puede atarnos cuando el conflicto político se decida de modos que a nosotros nos parecen inconvenientes e incluso perversos. Es entonces cuando queremos poder volvernos hacia algo que no dependa de los contingentes resultados de la política, algo que esté siempre ahí. Pero no hay nada. No sirve sujetar la mesa para evitar que se desplome el castillo de naipes cuando hay un terremoto. Sólo sirve intentar construirlo de la mejor manera posible, no para que soporte cualquier terremoto concebible, porque eso es imposible, sino para que soporte lo más posible, y esperar confiados que no haya uno más fuerte.

No quiero terminar con esta analogía, porque induce a creer que la suerte del proceso político depende de fuerzas que operan en su exterior. No cabe duda de que en algunos casos es así. Pero no, me atrevo a decir, en los más importantes. Y es importante decirlo aquí, en este auditorio, porque los abogados (a diferencia de los filósofos del derecho) siempre han sabido que el derecho no es una cosa que pueda ser descrita con independencia de lo que los participantes de nuestras prácticas jurídicas crean que es. Lo que he hecho en estas palabras finales es rescatar una concepción del derecho y de lo político distinta de la que subyace a las ideas hoy en boga sobre control de constitucionalidad. En esta visión, lo que nos han enseñado a mirar como un defecto de lo político, su contingencia, es su virtud. Riesgosa, si, pero su virtud. ¿Y el derecho? El derecho lo que hace es reducir la contingencia porque una de las razones por las que lo político tiene valor es que nos permite llevar nuestras vidas privadas. Esas vidas necesitan mecanismos de reducción de la contingencia, que nos permitan planificar nuestras vidas y vivir conforme a nuestros planes y no simplemente ser cuerpos a través de los cuales la vida es vivida. La política como contingencia, el derecho como negación de la contingencia. Si intentamos sujetar la política al derecho, podemos 
perder ambos: al derecho porque se hace contingente, vulgarizándose ${ }^{51}$; la política porque se hace no-contingente, en el sentido de que se transforma en una actividad puramente gerencial, reducida a simple racionalidad de medios, pues los fines a los que esa actividad gerencial se orienta ya están determinados por la constitución y sus intérpretes autorizados.

\section{Referencias}

Atria, F.: "Inaplicabilidad y coherencia: contra la ideología del legalismo", en 12 Revista de Derecho (2001): 119-156.

- 'Legalismo y reflexividad: la contraloría como modelo', en J Pallavicini y R Herrera (eds): La Contraloría General de la República y el Estado de Derecho (Santiago: Contraloría General de la República, 2002).

— "La hora del derecho. Los 'derechos humanos' entre el derecho y la política", en 91 Estudios Públicos (2003): 45-90.

- 'Legalismo, política y derechos', en M Alegre, A do Amaral, F Atria et al: Los Derechos Fundamentales (Buenos Aires: Editores del Puerto, 2003).

— "Ubi ius ibi remedium? La relevancia jurídica de los derechos humanos", en 3 Revista de Estudios de la Justicia (2003): 35-47.

— “Existen derechos sociales?” en 4 Discusiones (2004).

Boвbio, N.: Derecha e Izquierda (Madrid: Taurus, 1996), traducido por A Picone.

Boyle, A.: 'The World Trade Organization and Maritime Environment', en M H Nordquist, J N Moore y S Mahmoudi (eds): the Stockholm Declaration and the Law of the Marine Environment (The Hague: Kluwer, 2003).

CEA, J. L.: Derecho Constitucional Chileno. Derechos, deberes y garantías (Santiago: Editorial Jurídica de Chile, 2004).

Cohen, G. A.: Si Eres Igualitarista, ¿Cómo es que eres tan rico? (Barcelona: Paidos, 2001).

Comisión Nacional de Verdad y Reconciliación: Informe (Santiago: La Nación, 1991).

Detmold, M. J.: "Law as Practical Reason”, en 48 Cambridge Law Journal (1989): 436-471.

Dworkin, R.: 'Rights as Trumps' (1981), en J Waldron (ed): Theories of Rights (Oxford: Oxford University Press, 1984).

- Law's Empire (London: Fontana, 1986); también El Imperio de la Justicia (Barcelona: Gedisa, 1988), traducido por C Ferrari.

- El Imperio de la Justicia (Barcelona: Gedisa, 1988; edn orig 1986), traducido por C Ferrari.

Elster, J.: Ulises y las Sirenas (México: Fondo de Cultura Económica, 1989; edn orig 1979).

Hart, H. L. A.: The Concept of Law (Oxford: Clarendon Press, 1994; edn orig 1961); también El Concepto de Derecho (Buenos Aires: Abeledo-Perrot, 1963), traducido por G Carrió.

\footnotetext{
${ }^{51}$ Véase Atria, "La hora del derecho" 57-69.
} 
Hervé, D. y X. Fuentes: "La controversia del pez espada", en de próxima aparición en Estudios Internacionales (2004).

Kelsen, H.: ¿Quién debe ser el defensor de la constitución? (Madrid: Tecnos, 1935)1931), traducido por Brie, $R$.

— ¿Qué es la Justicia? (Buenos Aires: Leviatán, 1987; edn orig 1957).

- Teoría Pura del Derecho (México: Porrúa, 1991; edn orig 1960), traducido por R J Vernengo.

Locke, J.: Dos Ensayos sobre el Gobierno (Madrid: Espasa-Calpe, 1991)1690), traducido por Giménez, F.

Nino, C.: 'Los fundamentos del control judicial de constitucionalidad', en Ackerman, Rosenkrantz, Balbín et al: Los Fundamerntos y Alcances del Control Judicial de Constitucionalidad (Madrid: Centro de Estudios Públicos, 1991)1991.

Nozick, R.: Anarquía, Estado y Utopía (México: Fondo de Cultura Económica, 1990; edn orig 1974), traducido por R Tamayo.

Peña, C.: Práctica Constitucional y Derechos Fundamentales (Santiago: Corporación Nacional de Reparación y Reconciliación, s.f.).

Rawls, J.: A Theory of Justice (Cambridge, MA: Harvard University Press, 1971); también Teoría de la Justicia (México: Fondo de Cultura Económica, 1985), traducido por M D González.

- Teoría de la Justicia (México: Fondo de Cultura Económica, 1985)1971), traducido por M D González.

RAz, J.: 'Authority, law and morality', en Raz: Ethics in the Public Domain (Oxford: Clarendon Press, 1985)1994.

- Practical Reason and Norms (Princeton: Princeton University Press, 1992; edn orig 1975); también Razón Práctica y Normas (Madrid: Centro de Estudios Constitucionales, 1992), traducido por J Ruiz Manero.

Rosencrantz, C.: 'La pobreza, la ley y la constitución', en A Bullard, J Couso, R Gil Lavedra et al: El Derecho como Objeto e Instrumento de Cambio Social (Buenos Aires: Editores del Puerto, 2003).

Schmitт, C.: La Defensa de la Constitución (Barcelona: Labor, 1998)1931), traducido por Sánchez, M.

Sierra, L.: "Cuotas obligatorias de alumnos 'vulnerables' en la educación subvencionada: defectos constitucionales", en 266 Centro de Estudios Públicos: Puntos de referencia (2003).

TROPER, M.: "The logic of justification of judicial review", en 1 International COnstitutional Law (2003): 99-121.

Tushnet, M.: Taking the Constitution away from the Courts (Princeton, NJ: Princeton University Press, 1999).

Waldron, J.: Law and Disagreement (Oxford: Clarendon Press, 1999).

Weber, M.: Economy and Society (Berkeley: University of California Press, 1978; edn orig 1922). 